\title{
Design with nature: integrating green façades into sustainable buildings with reference to Abu Dhabi
}

\author{
M. A. Haggag, S. K. Elmasry \& A. Hassan \\ UAE University, United Arab Emirates
}

\begin{abstract}
Hot and arid climates, such as those in Al-Ain city in the Emirate of Abu Dhabi, UAE, generate unique challenges to architects who are seeking for high energy performance approaches to design buildings that are energy efficient, environmentally friendly, and architecturally remarkable. This paper introduces an on-going research which investigates potential improvements in the building performance when integrating green wall design strategies into sustainable buildings in hot climate. The study examines the performance of green facades in Abu Dhabi in minimizing the extensive heat gain by keeping solar energy from entering the indoor space as a strategy to save cooling demand. Green facade is a type of green wall systems in which climbing the plants are trained to cover supporting structures.

Liwa International School (LIS) was selected as a case study to investigate the performance of the integrated building façade with the application of green wall system in the hot climate of Al Ain city in the Emirate of Abu Dhabi. A vegetated living wall was installed on the building façades end of 2010. The experimental results showed that the green facade can maintain on average $5^{\circ} \mathrm{C}$ lower temperature during day time for the month of July than the bare wall which has substantial impact on reducing building cooling load.

Keywords: Abu Dhabi, energy efficiency, green wall, hot climate, thermal performance, sustainability.
\end{abstract}

\section{Introduction}

The Emirate of Abu Dhabi, the largest emirate by area, and the second largest by population after Dubai is divided into three major regions: Abu Dhabi City, the 
federal capital of the UAE; the Eastern Region; and the Western Region. Abu Dhabi has become one of the most modern cities in the Gulf region. The principles of architectural pattern in Abu Dhabi have moved from a traditional ideology which reflects the climatic condition and the cultures of the residents; to a modern style. Abu Dhabi is characterized by high temperature, humidity and sunshine. Summer daytime temperatures range from $35^{\circ} \mathrm{C}$ to $50^{\circ} \mathrm{C}$ however winter daytime temperatures range from $25^{\circ} \mathrm{C}$ to $35^{\circ} \mathrm{C}$. Despite that fact, the use of glazed façades has gained increasing popularity in the modern buildings approaches which usually come with an increased air-conditioning cost and energy consumption due to the high solar gain. At present, minimizing the negative impact on the natural environment and improving the ecological performance of urban are the main concerns of the new vision of Abu Dhabi 2030 master plan. These goals have been acknowledged by national and international developers and stakeholders in many cities of United Arab Emirates (UAE). Thus, energy efficiency and healthy environment are now the key issues in sustainable urban process in Abu Dhabi.

As part of an on-going study carried out by the authors in 2010, Liwa International School (LIS) which is located in Al-Ain City of the eastern region of the Emirate of Abu Dhabi was selected as a case study to investigate the performance of the integrated green façade into sustainable buildings in the hot climate. The school building was constructed in 1992 and converted from conventional to sustainable green building in 2010. The building is currently performing with green wall application, Photovoltaics, and grey water recycling strategies. An experimental approach was used to assess the effect of vegetation on the thermal performance of the school façade. To analyze the thermal performance of the green façade, the temperatures on the indoor and outdoor surfaces and ambient were recorded to investigate: a) the outdoor microclimate; b) the reduction of wall temperature; c) resistance to heat flow; and d) the reduction of cooling need. To determine the local cooling effect produced by the green façade on the external wall, the external surface temperature of the green façade is compared with the corresponding external surface temperature of the bare façade. The study demonstrates the potential benefits of green wall strategies to minimize the negative impact on the natural environment by increasing energy efficiency, providing sound insulation, protecting building surface, and creating more pleasant indoor spaces and air quality improvements. In this context, various issues are concerned: the performance of building skin in a sustainable context, green wall strategies, and lessons of experiences.

\section{Sustainable performance of building skin}

Sustainability refers to an ecological process characterized by the fulfilment of human needs while maintaining the natural resources. Sustainable building approach could be achieved by architects, engineers, and manufacturers of building products working cooperatively to produce green building skins in an ecological and resource efficient manner. Sustainable building skin is the 
practice of increasing energy efficiency, while reducing building impact on the environment [1].

The building skin is an important contributor to energy efficiency. It is considered a selective pathway for a building to work with the climate, responding to heating, cooling, ventilation, and natural lighting needs. It plays a dominant role on the overall energy performance by controlling heat transfer and solar radiation. It has to balance requirements for ventilation and daylight while providing thermal protection appropriate to the climatic conditions [2].

Building skin design should be integrated with other aspects including material selection, daylight, ventilation, and air-conditioning. Building function is an important factor in skin design. If the activity and equipment inside the building generate a significant amount of heat, the thermal loads may be primarily internal rather than external. This affects the rate at which a building gains or loses heat. Construction details and façade systems also play an important role in designing building skin. Appropriate detailing systems, including choice and placement of insulation material, are essential to guarantee the required level of thermal performance, which has to do with reducing heat transmission, which occurs in three ways: conduction, convection, and radiation (figure 1). Conduction is where heat passes through a building skin. The conductance of particular building materials or construction elements is the amount of heat that will be conducted through a unit area in unit time for unit temperature differences between the faces of building skin (thermal transmission coefficient U-value); the lower the U-value, the better the insulation (figure 2). In convection process, air flows collect heat from warmer surfaces and convey it to cooler ones. Radiation involves energy transfer by electromagnetic waves [2]. Construction engineers can reduce building skin related energy losses by reducing air leakage through the external skin, using high performance windows, increasing insulation levels, and minimizing thermal bridging. In terms of energy efficiency, the use of green wall strategies has gained popularity to minimize energy consumption. This concept can increase comfort, reduce operating costs, and reduce overall energy use and negative environmental impacts [3].

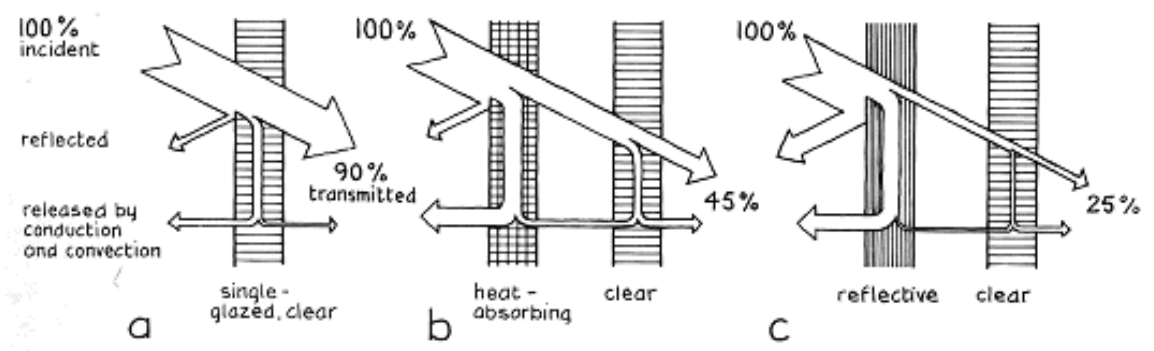

Figure 1: Typical reduction in solar transmission through a) Clear glass; b) Double glazed heat-absorbing glass; c) Double glazed reflective 'mirror' glass [2]. 


\begin{tabular}{|c|c|c|}
\hline & construction & $\begin{array}{l}u \\
\text { value }\end{array}$ \\
\hline \multicolumn{3}{|l|}{ wall } \\
\hline 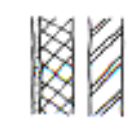 & $\begin{array}{l}\text { I0s mm outer brick leaf; } \\
\text { unventilated cavity; } \\
\text { loo mm lightwelght block } \\
\text { inner leaf; plaster }\end{array}$ & 0.95 \\
\hline 18 & $\begin{array}{l}\ldots \text { and with } 50 \mathrm{~mm} \\
\text { insulating slab in cavity }\end{array}$ & 0.70 \\
\hline 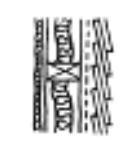 & $\begin{array}{l}\text { outer weatherboarding; } \\
\text { building-paper backing; } \\
\text { cimber frame; incorporated } \\
50 \mathrm{~mm} \text { glass-fibre quilt; foil- } \\
\text { backed plasterboard }\end{array}$ & 0.60 \\
\hline 语 & $\begin{array}{l}105 \mathrm{~mm} \text { brick outer leaf; } \\
\text { unventilated cavity: incorporated } \\
50 \mathrm{~mm} \text { quilt; polythene vapour } \\
\text { check; plaster board }\end{array}$ & 0.50 \\
\hline 率 & $\begin{array}{l}\text { window; single-glazed, wood } \\
\text { frome }\end{array}$ & 5.60 \\
\hline 西昲 & $\begin{array}{l}20 \text { and double-glazed with } \\
20 \mathrm{~mm} \text { airgap }\end{array}$ & 2.50 \\
\hline
\end{tabular}

Figure 2: $\quad$ Thermal transmission coefficient $\mathrm{U}$-value $\left(\mathrm{W} / \mathrm{m}^{2 \circ} \mathrm{C}\right)[2]$.

A natural passive cooling system is an option for sustaining a green building and reducing air conditioning costs. About $30 \%$ of the unwanted heat comes in through the building roof, and more than $40 \%$ through windows and walls [4]. To minimize the effect of radiant energy, a reflective waterproof coating and installation of a radiant barrier on the underside of the roof are essential. This can reduce heat gains by about $25 \%$ [4]. Light-coloured surfaces effectively reflect most of the heat. Reflective window coatings can also reduce the heat gain by about $35 \%$ [6]. Sun-coating films can reflect as much as $80 \%$ of the incoming sunlight [4].Green walls can also reduce heat gain and their surface temperature is lower than an exposed wall. Based on the analysis carried out by Green over Grey firm [5], studies have shown that the external surface of a green wall is up to $10^{\circ} \mathrm{C}$ cooler than an exposed wall; therefore the $\mathrm{U}$-value for the green wall is usually lower and helps to reduce cooling loads [5].

Natural ventilation helps remove heat and maintains indoor temperatures close to outdoor temperatures. This strategy only works when the inside temperature is higher than outside temperature. In hot climates, a building designed for passive cooling would be as open as possible to ensure the maximum possible cross ventilation [6]. East and west walls should have a minimum of windows in order to exclude the low angle sun-rays. However, north and south walls should have enough windows to allow cross ventilation. A thermal chimney can be used to ensure ventilation by creating a warm zone with an exterior outlet. 


\section{Green wall performance}

Green wall systems are increasing in popularity due to its proven success in lowering the heat-island effect in the urban context, and its contribution towards achieving high comfort levels in spaces. Green wall is used as a term for both living walls and green façades. Living walls, also known as bio-walls are composed of pre-vegetated panels or integrated fabric systems that are fixed vertically to a structural wall or frame [7]. Green façades are made up of climbing plants that growing directly on a wall or supporting structure. The plant grows up the wall while being rooted to the ground, in intermediate planters or on the rooftops. Rigid panels and cable systems can be used to hold vines off the wall surface.

A number of studies have been conducted to explore the thermal effect of vertical green surfaces on building skins. In Canada, there is proven evidence that vertical greenery systems can reduce air conditioning load by shading walls and windows from incoming solar energy resulting in a $5.5^{\circ} \mathrm{C}$ reduction in the outdoor ambient temperature wherein shading effect was found to reduce cooling load by about $23 \%$ and the usage of fans by $20 \%$ resulting in an $8 \%$ reduction in annual energy consumption [2].Through simulation, a100\% greenery coverage with plants of higher shading coefficient, proved to achieve about $18 \%$ drop in cooling load [8]. Also the study highlights that a lower shading coefficient results in better greenery effectiveness on glass facades. Given that the thermal transfer value of the building skin and the leaves coverage of a plant are useful design variables when it comes to achieve the intended amount of thermal load reduction $[10,11]$.

Alexandri and Jones highlight the importance of the green walls in reducing the heat island effect in microclimates [12]. They conclude that in hotter and drier climates, the greater is the effect of vegetation on urban temperatures. The study highlights that temperature decrease is primarily affected by the vegetation itself, as well as orientation. The study suggests that if applied to the whole city scale, green roofs and walls could mitigate raised urban temperatures, and especially for hot climates, achieve energy saving for cooling buildings may range from $32 \%$ to $100 \%$.

In addition to their significant thermal benefits, plantations have been used as barriers against urban noise pollution. Green walls have an acoustical insulation that is far better (up to $30 \mathrm{db}$ ) than that of exposed wall [13]. The degree of sound insulation provided by the green wall depends mainly on factors that influence noise reductions including depth of the growing media, type of plants, materials used for the structural components of the living wall system, and the layer of air between the plants and the wall.

Green wall technology can protect building surfaces and extend the lifespan of the building skin by reducing surface temperature of a building skin, and using appropriate techniques such as waterproof living wall panels. This protection comes mainly from keeping rain off the building while allow moisture to escape, reducing the expansion and contraction of building materials, and protecting walls against wind and solar radiation which might affect the building 
materials. Green wall technology has a visual impact on buildings, and it can help to address the lack of green space in urban environments. Plants improve human health, capture airborne pollutions, and filter harmful gases.

\section{Case study: Liwa International School, Al-Ain}

Liwa International School (LIS) is located in the south west end of Al-Ain City at latitude $24^{\circ} 16^{\prime}$ and longitude $55^{\circ} 36^{\prime}$ E. LIS has participated in the World Future Energy Summit 2010 with a sustainable green building project. This project aimed to convert the school from conventional to sustainable green building by reducing energy consumptions and increasing energy efficiency. Three systems were adopted: a) Green wall application, aiming at reducing heat gain; b) Photovoltaic panels installed on the roof to provide power for lighting and irrigation systems; and c) Grey water recycling system. As part of the ongoing experimental work which is carried out by the authors, the green façade of LIS is examined as a case study to investigate the performance of the integrated building façade with the application of green wall system in the hot climate of $\mathrm{Al}$ Ain city.

A vegetated wall was installed on the building facades as shown in figure 3 . The system is composed of plastic boxes $(30 \times 3025 \mathrm{~cm})$ installed connectively on the facades; drip irrigation pipes; and plant foliage.
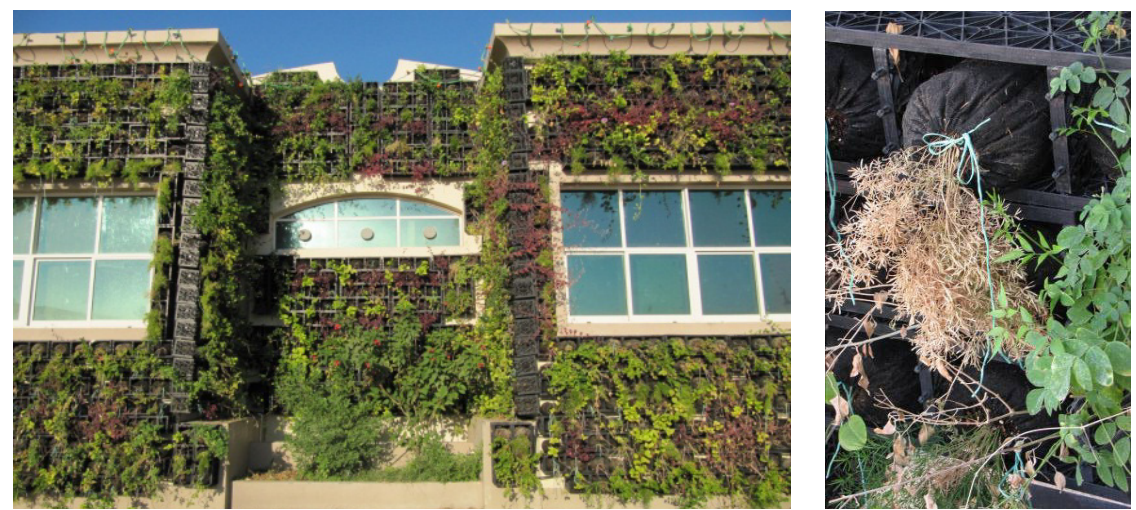

Figure 3: Green wall installation, Liwa International School, Al-Ain.

\section{Measurements procedure}

PTFE insulated T-type thermocouples were fabricated and calibrated with an error range of up to $\pm 0.5^{\circ} \mathrm{C}$ to measure temperatures. Two identical class rooms (width: $5 \mathrm{~m}$; length: $7 \mathrm{~m}$; and height: $3.5 \mathrm{~m}$ ), one bare and the other with green wall both facing East were selected and two Omega (DaqPRO) data loggers were used to measure temperature at four locations i.e. ambient air temperature $1 \mathrm{~m}$ away from wall, air temperature in the middle of green vegetation, external 
surface temperature of wall, internal surface temperature of wall and internal air temperature of the room. In case of room with green wall temperature was measured in middle of green wall in addition to the four mentioned measurement locations. The data was recorded every 10 minutes and measurement scheme was run from $1^{\text {st }}$ July 2011 to $1^{\text {st }}$ August 2011 to avail higher ambient temperatures and higher solar radiation intensity in order to observe the maximum impact of green wall on cooling of the indoor spaces.

\section{Results and discussion}

\subsection{Thermal regulation effect of green wall}

In order to determine the temperature regulation effect of green wall on indoor environment, temperatures at three points are plotted, i.e., external surface temperature, internal surface temperature and internal ambient temperature for seven consecutive days as shown in figures 4,5 and 6 . It shows that the external surface temperature on bare wall went above $56^{\circ} \mathrm{C}$ while the temperature on green wall remained at below $50^{\circ} \mathrm{C}$ for almost all the seven days. It can be observed that for the whole duration of the experiment in the month of July, the external surface temperature remains highest while internal surface and ambient temperature remain also high enough for both the green and bare walls which shows a higher need for cooling. In case of green wall, all the three temperatures are consistently lower than the bare wall which shows the thermal regulation potential of the green wall.

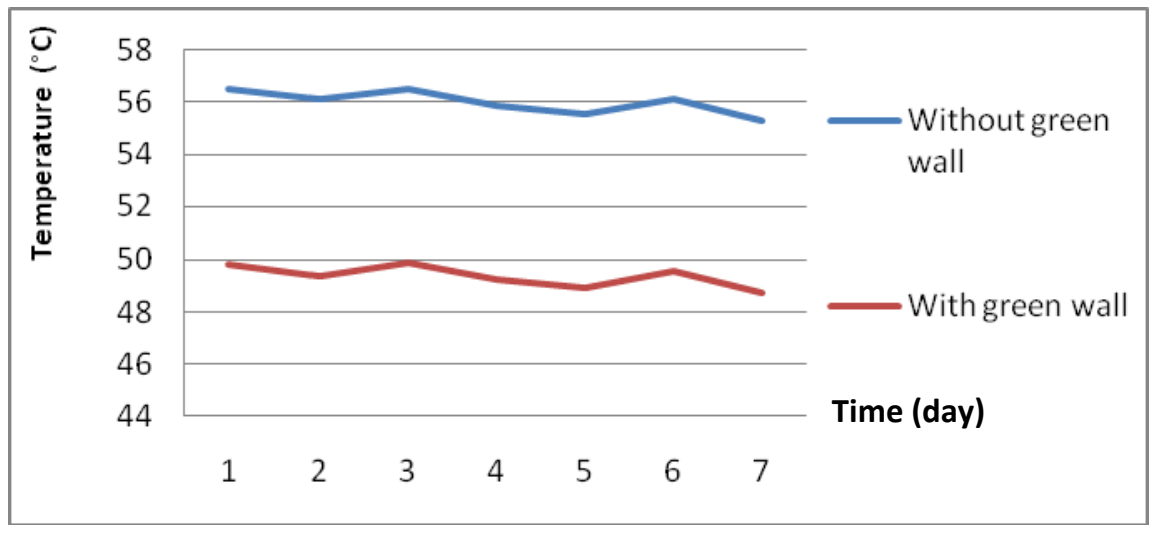

Figure 4: External surface temperature of the bare and green wall for seven days of measurements in July 2011 in Liwa International School. 


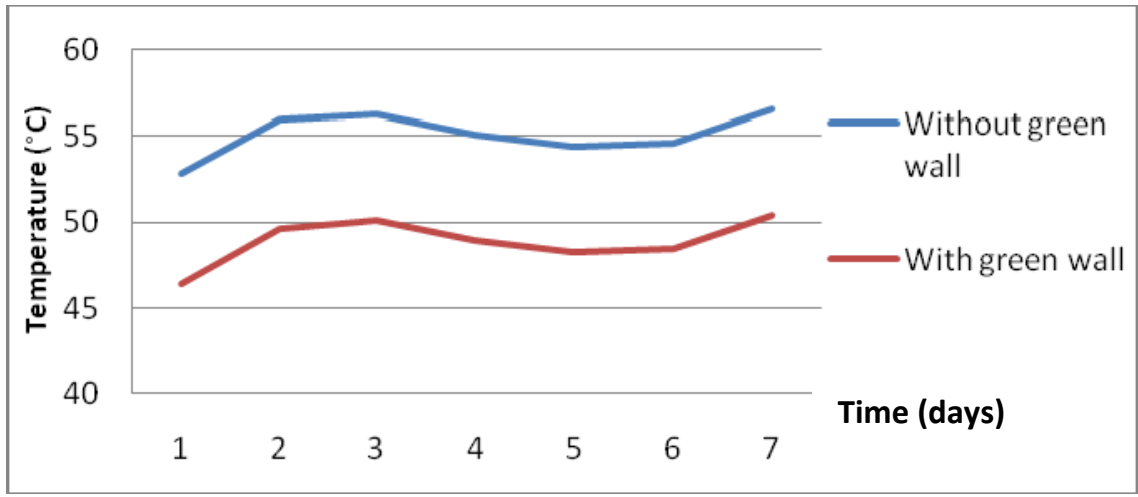

Figure 5: Internal surface temperature of the bare and green wall for seven days of measurements in July 2011 in Liwa International School.

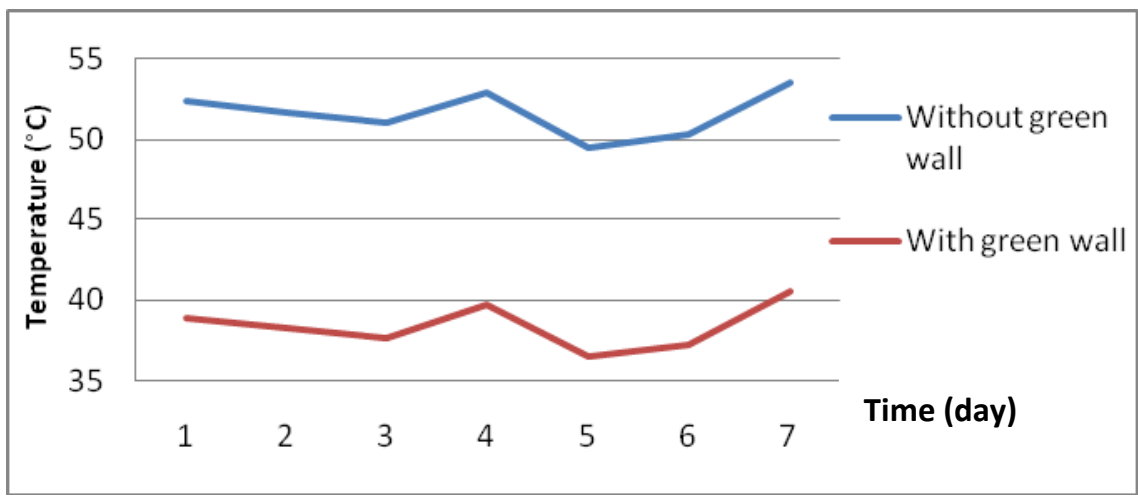

Figure 6: Internal air temperature of the bare and green wall for seven days of measurements in July 2011 in Liwa International School.

\subsection{Insulation effect of green wall}

The external, internal and indoor temperature differences between bare and green walls are shown in figures 7,8 and 9 respectively. figure 9 shows that temperature difference between bare and green wall is consistently above $5^{\circ} \mathrm{C}$ reaching up to $13^{\circ} \mathrm{C}$ at peak. It can be seen in figure 7 the temperature difference between the bare wall and green wall is positive during day time which reduces the cooling load of building however at night time the temperature difference is negative which means in the absence of green wall the surface external cools faster than with green wall. This shows that in a colder climate, this insulation effect of green wall can be exploited to keep the heat absorbed indoors during day time escape to outdoors and keep the space warmer for thermal comfort and reducing heating load. In hot climates, this would tend actually reverse the ambient cooling effect at night by reducing external wall cooling rate. 


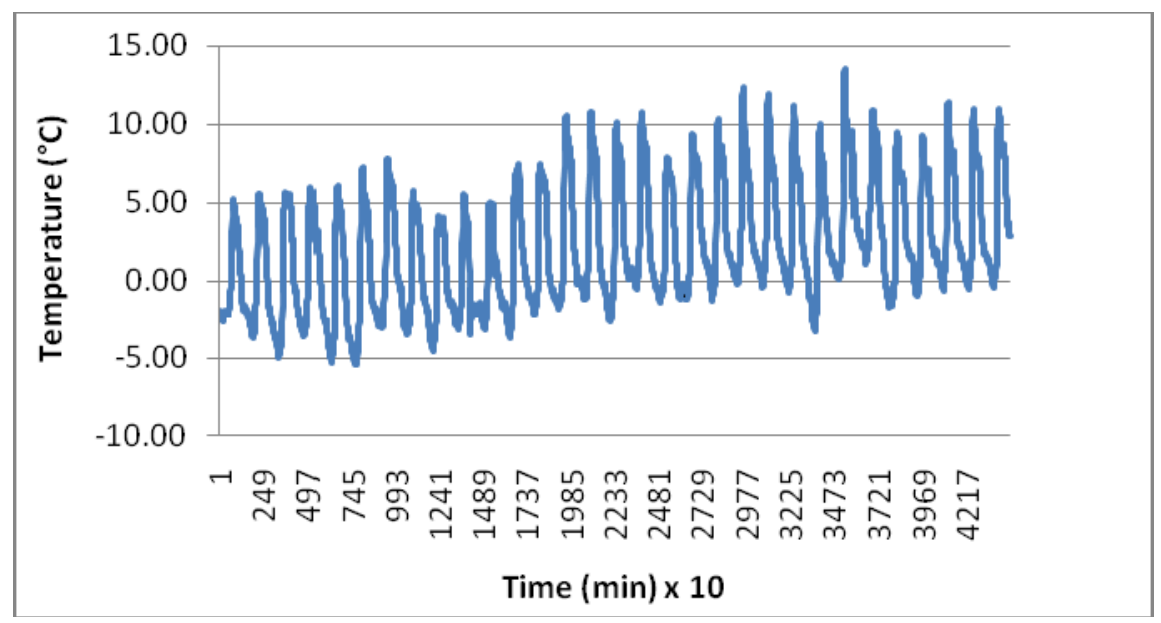

Figure 7: External surface temperature difference of the bare and green wall for seven days of measurements in July 2011 in Liwa International School.

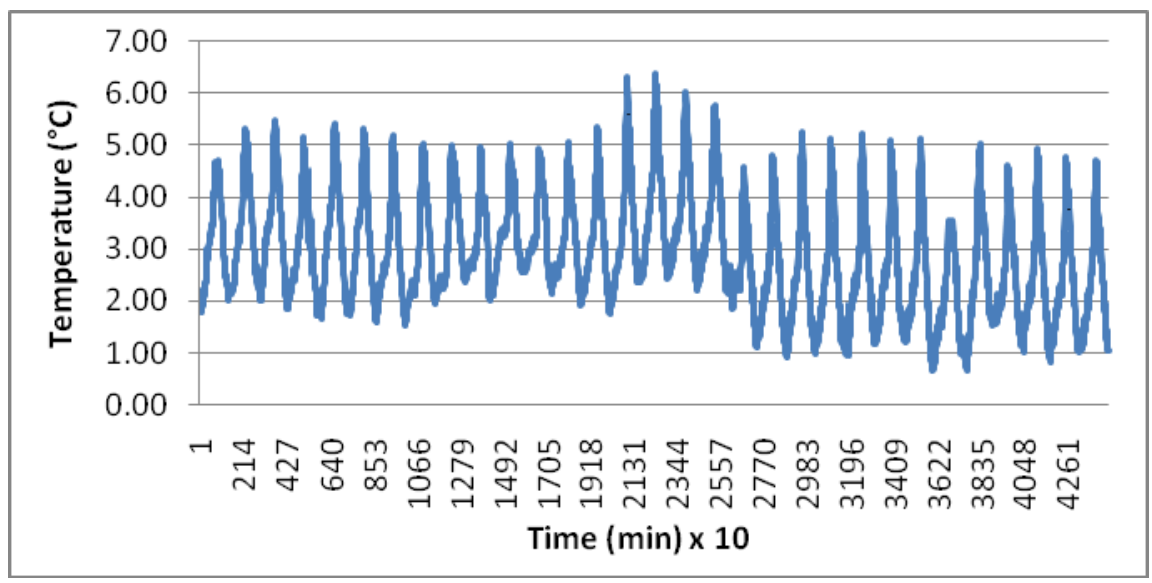

Figure 8: Internal surface temperature difference of the bare and green wall for seven days of measurements in July 2011 in Liwa International School.

It can be seen in figure 8 that the green wall internals surface remains always cooler than the bare wall surface, with a consistent temperature difference of above $4^{\circ} \mathrm{C}$ reaching up to $6^{\circ} \mathrm{C}$ during peak time of the day and above $1^{\circ} \mathrm{C}$ reaching up to $2.5^{\circ} \mathrm{C}$ during lowest peak at night. Figure 8 shows the internal surface temperature difference of bare wall and green wall an all positive trend which shows that in both day and night conditions the green wall maintains lower temperature than bare wall ad saves energy. Although from figure 7 the 


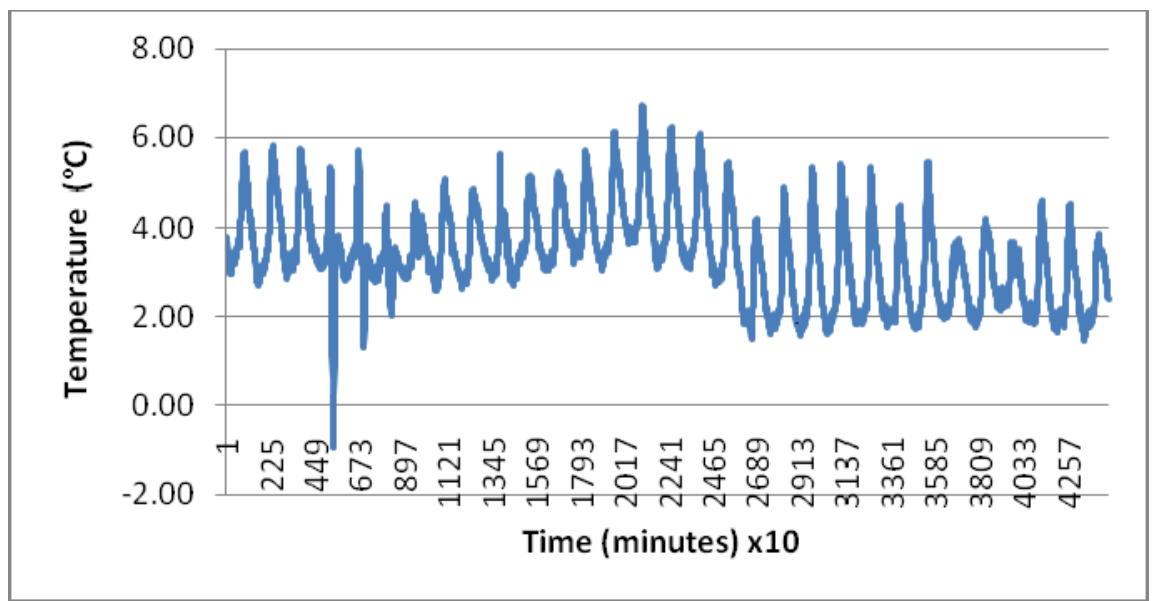

Figure 9: Internal surface temperature difference of the bare and green wall for seven days of measurements in July 2011 in Liwa International School.

bare wall tends to cool faster than green wall at night, figure 8 shows it has least effect on the internal surface due to thermal mass of the wall.

Figure 9 shows indoor ambient air temperature difference between bare and green walls and it can be seen that green wall always maintains lower temperature than bare wall regardless of day and night ranging from $2{ }^{\circ} \mathrm{C}$ during night time to almost $6^{\circ} \mathrm{C}$ during peak day time. Although at night the temperature difference is generally lower which shows green wall saves more energy during day time than night by keeping the space from overheating. At night the effect is lesser due to the fact that at start of night bare wall is at much higher temperature compared to green wall, however bare wall cools faster than green wall and tends to reduce the temperature difference.

\section{Conclusion}

The use of green wall was successfully adopted in the Emirate of Abu Dhabi, UAE to increase energy efficiency in buildings and reduce environmental impact. It also increases sound insulation and create more pleasant indoor spaces and air quality improvements. The decreased temperature on the green facades are achieved by: a) decreased heat gain into the green wall due to incident radiations being blocked by the vegetation leaves, soil mass, and the assembly carrying the plants; b) the evaporative cooling caused by the irrigation water to the plants; c) heat resistance due to low thermal conductivity of the plants acting as heat insulators to the ambient heat gain by the wall. This technology can reduce day time indoor air temperature by $5^{\circ} \mathrm{C}$ for the month of July 2011 , and reduce the air conditioning energy demand by up to $20 \%$. Green wall technology 
contributes directly to LEED credits since it covers issues like sustainability, energy saving, air quality, and sound reduction.

\section{Acknowledgements}

The authors would like to express their appreciation to the Research Affairs at the UAE University for their financial support, and cooperation in the research project entitled "Double Skin Façades with Integrated Vertically Greenhouse for Low Energy Building Performance; with Reference to Abu Dhabi”. Special thanks go to the research team members of Liwa International School for their appreciated help and support.

\section{References}

[1] Wheeler, S. and T. Beatley, 2004, The Sustainable Urban Development, New York.

[2] Reid, E., Understanding Buildings: a Multidisciplinary Approach, Longman, London, 2001.

[3] Haggag, M., "Building Skin and Energy Efficiency in Hot Climate, with Particular Reference to Dubai, UAE", First International Conference on Energy and Sustainability, 2007, The New Forest, UK

[4] www.empowementzon.com

[5] Green over Grey - Living Walls and Design, www.greenovergrey.com

[6] www.arch.hku.hk

[7] Caplow, T. et al., Vertically Integrated Greenhouse: Realizing the Ecological Benefits of Urban Food Production, Proceeding of The Ecocity World Summit, San Francesco, USA, 2008.

[8] Becker, R. et al., Improving energy performance of school buildings while ensuring indoor air quality ventilation, Building and Environment, 42, pp. 3261-3276, 2007.

[9] Wong, N. et al., Energy simulation of vertical greenery systems, Energy and Buildings, 41, pp.1401-1408, 2009.

[10] Eumorfopoulou, E. \& K. Kontoleon, Experimental approach to the contribution of plant-covered walls to the thermal behavior of building envelopes, Building and Environment, 44, pp.1024-1038, 2009.

[11] Alexandri, E. \& P. Jones, Temperature decreases in an urban canyon due to green walls and green roofs in diverse climates, Building and Environment, 43, pp.480-493, 2008.

[12] Glicksman, L. et al, Double skin, airflow facades. Proc. of the International Conference on Building Envelope Systems and Technologies, Ottawa: Canada, Vol. 1, pp.203-207, 2001. 